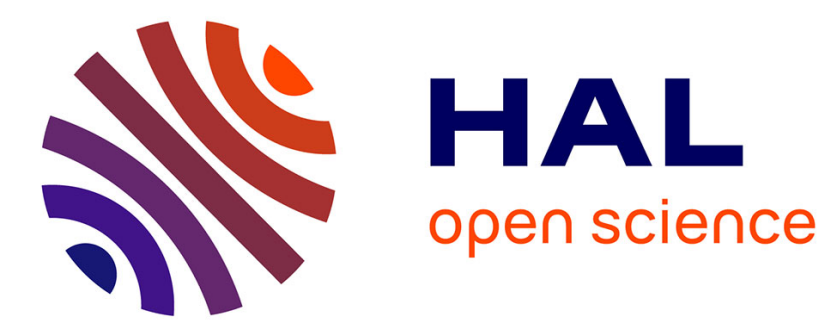

\title{
Gas Discharges Studies in Japan and some of my Own Researches
}

S. Takeda

\section{To cite this version:}

S. Takeda. Gas Discharges Studies in Japan and some of my Own Researches. Journal de Physique IV Proceedings, 1997, 07 (C4), pp.C4-133-C4-139. 10.1051/jp4:1997409 . jpa-00255565

\section{HAL Id: jpa-00255565 https://hal.science/jpa-00255565}

Submitted on 1 Jan 1997

HAL is a multi-disciplinary open access archive for the deposit and dissemination of scientific research documents, whether they are published or not. The documents may come from teaching and research institutions in France or abroad, or from public or private research centers.
L'archive ouverte pluridisciplinaire HAL, est destinée au dépôt et à la diffusion de documents scientifiques de niveau recherche, publiés ou non, émanant des établissements d'enseignement et de recherche français ou étrangers, des laboratoires publics ou privés. 


\title{
Gas Discharges Studies in Japan and some of my Own Researches
}

\section{$\underline{\text { S. Takeda }}$}

\section{1-12-19 Gakunanchou, Okayama 700, Japan}

\begin{abstract}
The charge distribution on an insulating sheet induced by a surface discharge can be directly observed by "Dust figure". "Discharge chamber" is a sensitive high energy particle detector with a luminous trajectory. The high frequency breakdown voltage as a function of $\mathrm{pl}$ and $\mathrm{fl}$ is an extension of Paschen's law in de discharge. The recombination loss predominant to attachment one was found in an afterglow of water vapour with the high electron density of plasmas by the phase angle of the reflection coefficient of a wave. The ripple of the electron temperature of high frequency produced plasma was measured as function of frequency for various pressures. An improvement of a laser interferometer to eliminate the fluctuation of the detected signal induced by the mechanical vibration of the system is developed.
\end{abstract}

\section{DISCHARGE STUDIES IN JAPAN}

The earliest studies of gas discharges in Japan, related to the high voltage engineering and insulation problems in the atmosphere, started more than seventy years ago. In associating with the industrial people and their support, basic researches were also carried out.

A few examples of interest for me will be mentioned here. The first one is "dust figure" technique developed by Prof. Toriyama [1], as shown in Fig.1. A needle electrode is in contact with an insulating sheet put on a metal plate. If the sheet is replaced by a photographic film, the "Lichtenberg" figure is recorded. After a pulse voltage is applied to the electrode, two kinds of colours powder are scattered on the sheet. Then each powder accumulates on positive and negative charges distributed on the sheet along the streamer produced by the surface discharge. Thus the distribution of each charge can be clearly observed.

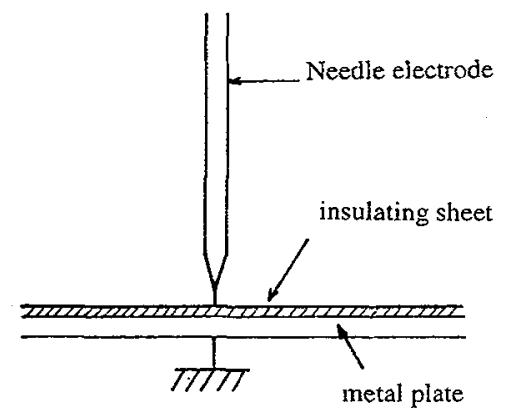

Figure I : Arrangement of dust figure

The second example is "discharge chamber" for a high energy particle detector invented by Prof. Fukui [2], as shown in Fig.2. The chamber consists of the glass box filled with Ar or Ne-Ar mixture at atmospheric pressure. When a pulsed voltage is applied to the electrodes immediately after the passage of the ionizing particle, the luminous discharge shown in left corner in Fig.2 
appears along the trajectory. The pulsed voltage is triggered by the output signal from a G.M. counter. I heard that the chamber was widely used through out the world.

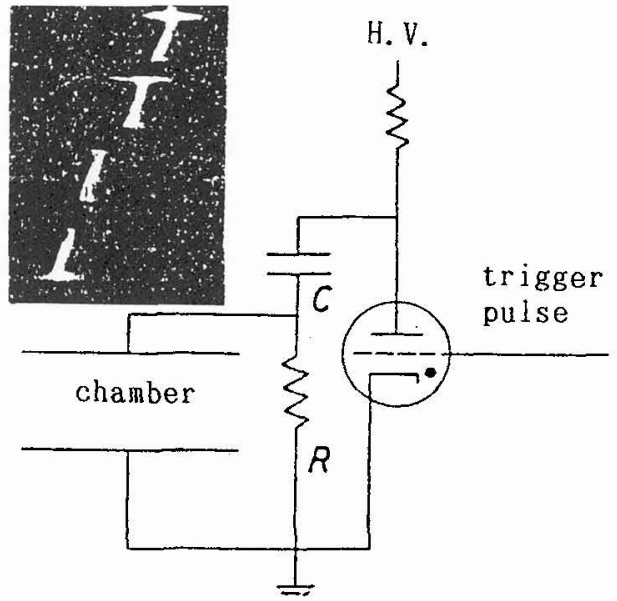

Figryure 2 : Arrangement of discharge chamber

The low pressure discharges were also studied. The third example for interest for me is the back-fire, which sometimes appeared in the arc of the $\mathrm{Hg}$ rectifier. It supplies the dc power to the electric train to drive its motor. Although the problem was extensively studied, the investigation stopped before a perfect understanding of the mechanism was reached, since the rectifier was replaced by the solid state devices.

Recently, high frequency plasmas found wide use in plasma processings and other discharge applications. Since such new topics are extensively discussed in the respective conferences, I am not going to dwell on these problems.

Following are some of my own researches.

\section{HIGH FREQUENCY BREAKDOWN}

During the second war, a triode tube for a long wave length was used in the radar system. When an aircraft carried the device and flew in high altitude with decreased pressure, frequent high frequency breakdown troubles between the electrodes outside the vacuum tube were reported. At that time the sufficient data of high frequency breakdown were not available.

After the war, $\mathfrak{l}$ attend to investigate the breakdown in broad ranges of frequencies and pressures. Using a simple theoretical consideration and numerous experimental data, I classified various ranges in a (pl-fi)-plane and made empirical formulae of the breakdown voltages Vs in each range as function of $\mathrm{pl}$ and $\mathrm{fl}$. This is an extension of Paschen's law in dc discharge.

The various range are shown in Fig.3 [3]. When $f$ is low, Vs goes to dc values [range (1)]. When $f$ increases, the oscillating ions are trapped between the plane electrodes and deform the electric field, resulting the increase of the $\gamma$-action of ions. Then Vs somewhat decreases [range (2)]. When $f$ is higher, the electrons are trapped between the electrodes and Vs again decreases by the enhanced ionization efficiency due to their long life time. The decrease is quite sharp in low pressures [range (3)]. When $f$ is further increased, the movement of trapped electrons become less active for ionization and Vs increases [range (4)]. When the electron mean path is longer than 1, the vacuum discharge appears and Vs is quite high [range (5-6)]. For high fl, Vs is low and increases [range (7)]. Fig.4 shows the contour lines of Vs in the (pl-fl)-plane, much like isohypses on a map. Fig. 5 shows a solid model of Vs as a function of $\mathrm{pl}$ and fl. Since the computer graphic techniques were not available at that time, the model was handmade of clay. The figure in the right is the model seen from the reverse side. If a plane of constant fl cuts the model, the dependence of Vs on $\mathrm{pl}$ is obtained. And if a plane of constant pl cuts it, the dependence of Vs on $\mathrm{fl}$ is obtained. 


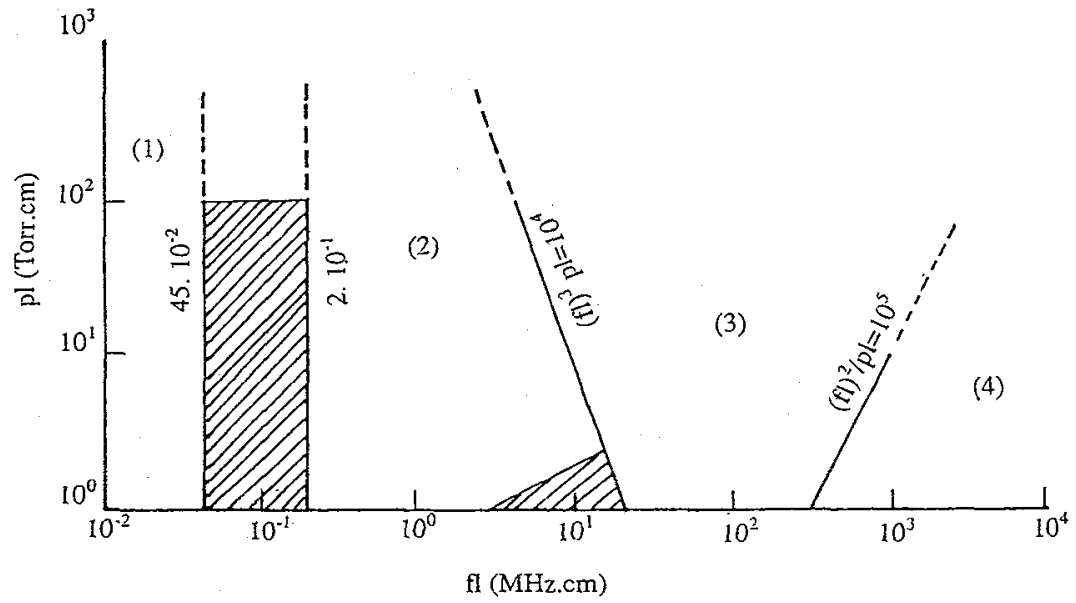

Figure $3:$ Ranges of $V_{s}$ in (pl-fl)-plane

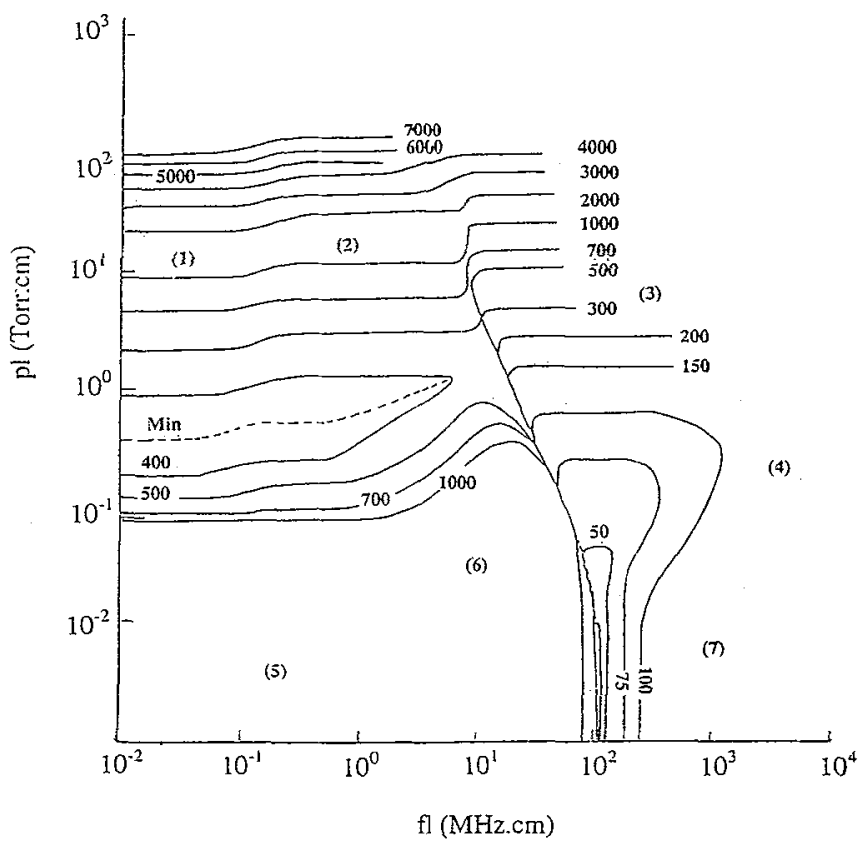

Figure 4 : Contour lines of $\mathrm{Vs}$ in (pl-fl)-plane

Almost at the same time, Prof. Brown [4] of MIT published a paper, which showed E/p as a function of $\mathrm{pl}$ and $\mathrm{p} \lambda$ ( $\lambda$ is the wave length) and included a corresponding theory of microwave frequency domain. Prof. Honda [5] in our country also independently published a theory with the same idea but with a different final expression. 

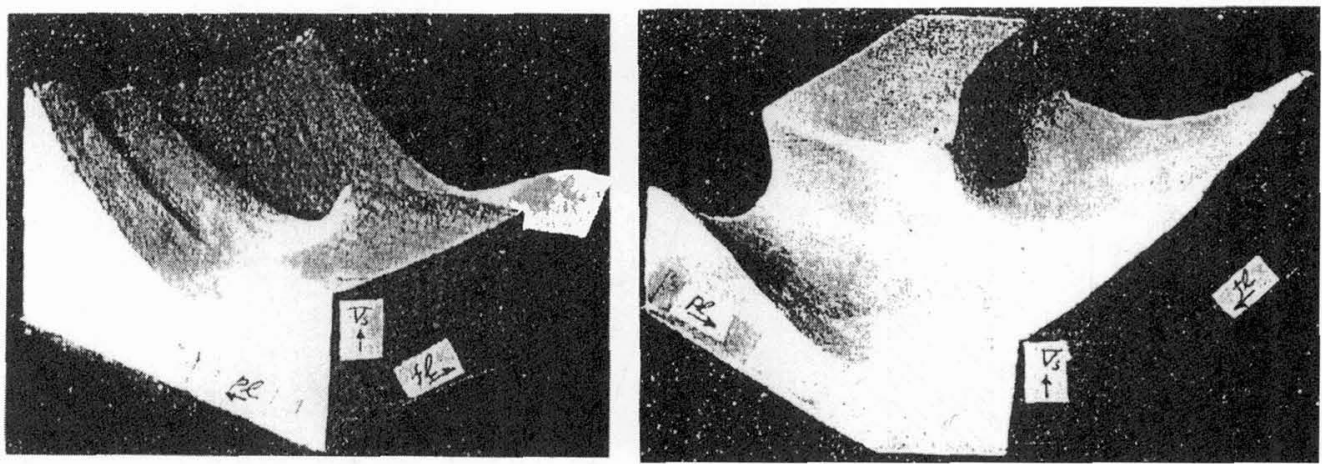

Figure 5 : Solid model of Vs

\section{AFTERGLOW IN WATER VAPOUR}

Being stimulated by afterglow studies of Prof. Brown, I was eager to start the research. However, since the elaborate microwave equipments were not available and the vacuum system in my laboratory was poor, I joined a group at the University of Illinois directed by Prof. Goldstein and Prof. Dougal.

They used the wave of $9000 \mathrm{MHz}$, which propagated through a long discharge tube installed in a waveguide. By measuring the wave characteristics, they determined the electron density $\mathbf{n}$ and the collision frequency $v$. Contrary to the $3000 \mathrm{MHz}$ wave in a cavity at MTT, the electron density of $10^{11} \mathrm{~cm}^{-3}$, which is one order of magnitude higher than that at MIT, could be measured. Thus they had already succeeded in detecting the electron-ion collision frequency in a weakly ionized plasma of high density and the low electron temperature.

The theme that I proposed was afterglow in water vapour. Discharge tube filled with argon mixed with water vapour was used in the radar system for separating the transmitting and receiving signals. It was assumed at that time that the water vapour helps to decrease the de-ionization time by its attachment process to find an object in a short distance. After my careful experiment, I found that the recombination loss surpassed the attachment one in plasmas of high electron density and low electron temperature. In addition, the collision probability, which is proportional to the collision cross section of electrons with molecules was determined as a function of the electron energy. When I presented the result at Gaseous Electronic Conference held in 1958, Dr Hull also reported the similar result with somewhat different value. Both data are shown with the theoretical line in Fig.6 [6].

\section{MEASUREMENTS OF HIGH ELECTRON DENSITIES}

After I was back to my country, I developed [7] a method to measure the high electron density for high values of the ratio $\omega_{\mathrm{p}}{ }^{2} / \omega^{2}=\eta$, which is proportional to the electron density. When a wave reflects at a sharp boundary of a plasma, the reflection coefficient $|\mathrm{R}| \mathrm{e}^{\mathrm{j} \theta}$ is calculated as a function of $\eta$. Fig. 7 shows the absolute value $|R|$ It increases toward unity at $\eta=1$ and remains constant beyond $\eta=1$. However, the phase angle $\theta$ changes from zero at $\eta=1$ to $180^{\circ}$ for the extremly high $\eta$ s which correspond to a perfect conductor. Thus, the local electron density can be determined by measuring $\theta$. The electron density from $10^{13}$ to $10^{16} \mathrm{~cm}^{-3}$ are measurable by using an $8 \mathrm{~mm}$ wave.

By inserting a waveguide into a plasma, the standing wave in the guide is represented by a real line, shifted from that for a perfect conductor (dotted line), as shown in Fig.8. The dotted line is realized by closing the end of the waveguide by a metal plate. For the plasma measurement the end of the waveguide is covered by a thin mica sheet to keep the plasma from penetrating into the waveguide filled with air. When the phase difference between $180^{\circ}$ and $\theta$ is measured, $n$ can be determined. Moreover, the standing wave ratio changes by the loss due to the collisions. Thus $\mathbf{n}$ and 
$v$ can be determined from $h_{1}$ and $h_{2}$ at the positions of a half and a quarter wave length distances from the end. If $h_{3}$ and $h_{4}$ are used, more accurate values for the smaller phase shifts can be measured.

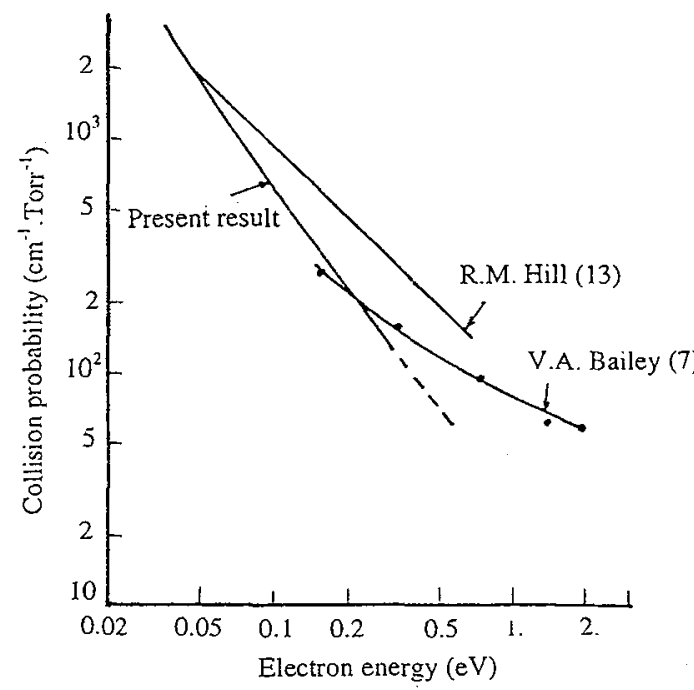

Figure 6 : Collision probability versus electron energy

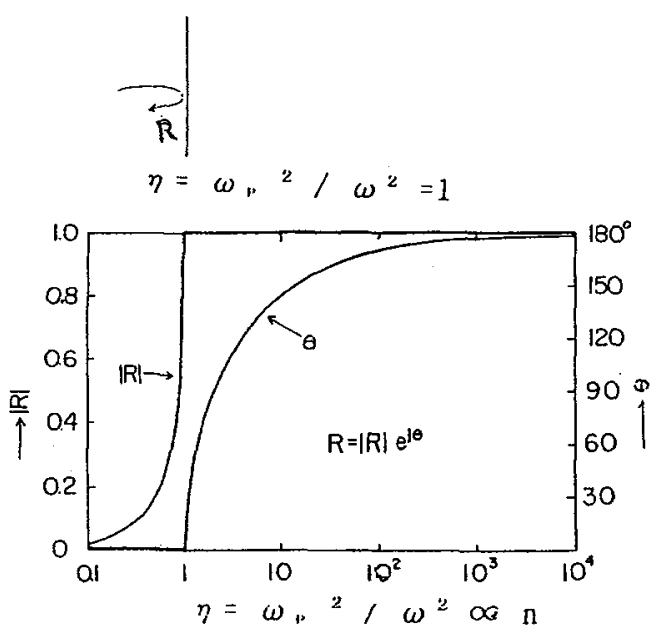

Figure $7:|\mathrm{R}|$. and $\theta$ versus $\eta$

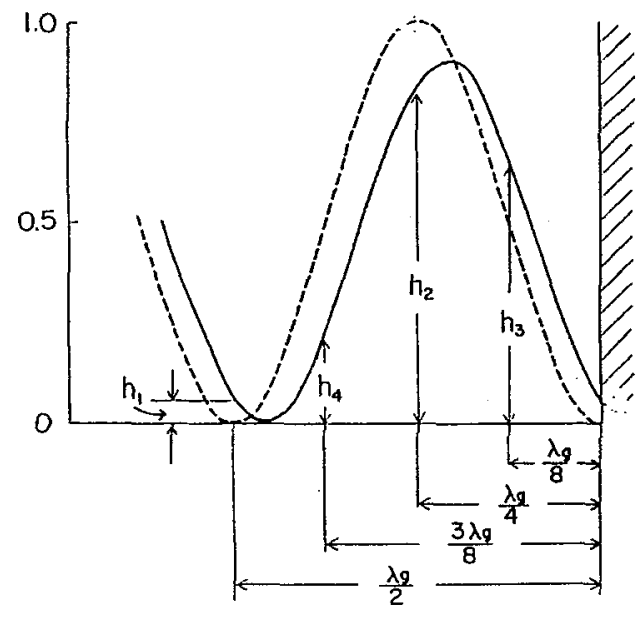

Figure 8 : Standing waves for a perfect conductor and a plasma

Since the skin depth penetrating into the plasma just after the reflection is much longer than the sheath width, its non-uniform electron density can be perfectly neglected for the calculation. I tried to measure the electron densities of $10^{14}-10^{15} \mathrm{~cm}^{-3}$ by this technique in a shock-wave produced plasma. The values were in a fairly good agreement with those obtained by the spectroscopic methods, namely, Stark broadening.

Here I add that Prof. Simonet [8] developed a method of measuring the position of cutoff or $\eta=1$ from the phase angle of the reflection coefficient and determined the density profile by using a swept-frequency oscillator. 


\section{RIPPLE OF ELECTRON TEMPERATURE}

Recently, high frequency produced plasmas are widely used for processings. I studied the ripple of the electron temperature of such a plasma. The measured ripples, defined as the ratio of the amplitude to the mean value, were plotted in Fig.9 [9], as a function of a frequency, for various pressures. Since the density fluctuation was neglected in the range of parameters studied, the ripple could be deduced from the observed emitted-light intensity. The result agreed well with the theoretical calculation which predicts that the ripple is inversely proportional to the frequency.

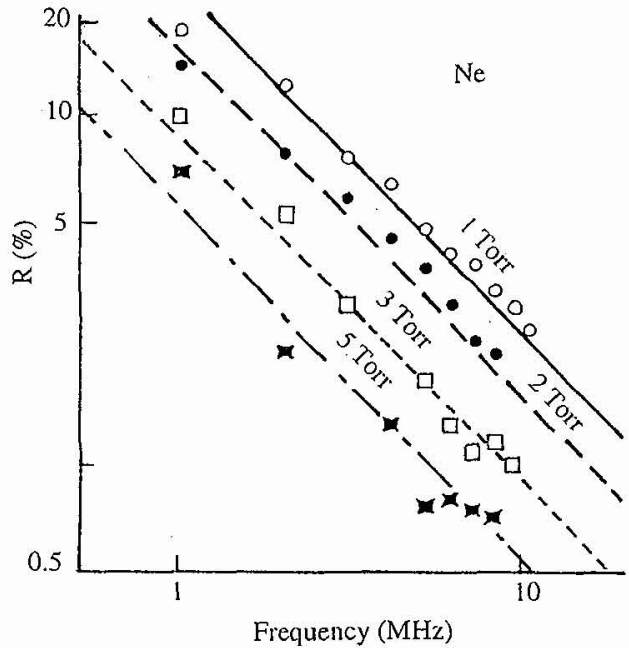

Figure 9: Ripple of electron temperature

\section{IMPROVEMENT OF LASER INTERFEROMETRY}

Recently, the laser interferometer became widely used to measure high electron densities of plasmas. When the wave length is comparable to the amplitude of the mechanical vibration of the system, a careful arrangement is required to eliminate the effect. An improvement by Prof. Yasuda [10] was developed for this purpose. Fig. 10 shows the total system. Two Ne-He lasers, with wave lengths of $0.63 \mu \mathrm{m}$ and $3.39 \mu \mathrm{m}$ respectively are used as sources of light which passes through a Michelson interferometer. A mirror a the right corner is driven by a magnetic coil of a loud speaker. The detected signal from $\mathrm{PD}_{1}$ is fed back to the moving coil after being reversed and amplified. Then the mirror can compensate the varying signals induced by fluctuation of the light path due to the mechanical vibration. Another wave of $3.39 \mu \mathrm{m}$ is used as the usual way of the interferometry. This is an automatic stabilization technique. Fig. 11 shows the fringe pattern from PD $_{1}$ without and with stabilization. To confirm the principle, Prof. Yasuda measured the refractive index of air with variable pressures. The values agreed well with the theoretical ones.

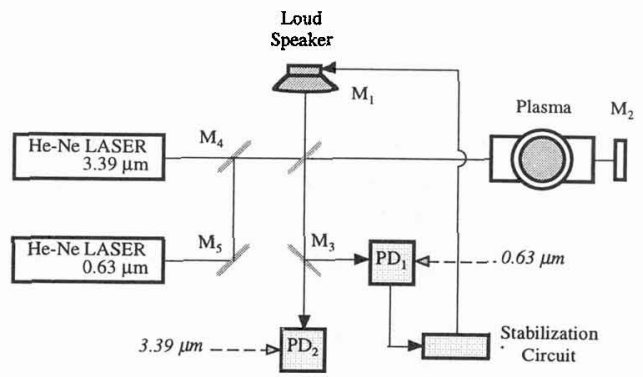

Figure 10 : Stabilization system of a laser interferometer 


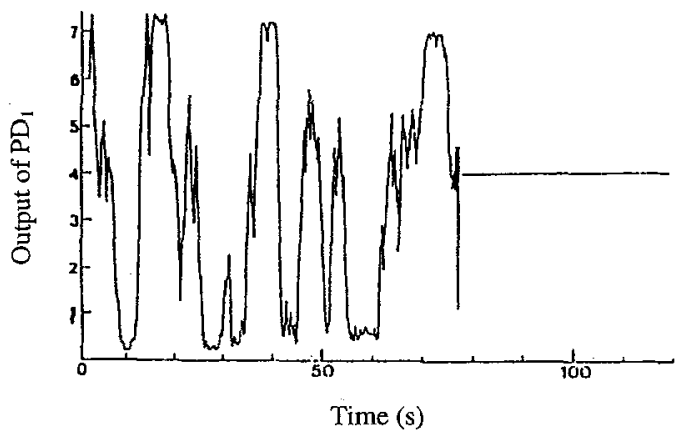

Figure 11 : Signal of $\mathrm{PD}_{1}$ without and with the stabilization

\section{Acknowiledgements}

Finally I would like to thank the International Scientific Committee members for awarding me Penning prize.

\section{References}

[1] Toryyama Y., Arch. Elektrotech, 28(1934) 105

[2] Fukui S. and Miyamoto S., Nuovo Cimento, 11(1959) 113

[3] Takeda S., Japan I.E.E.72 (1952) 753

[4] Herlin M.A. and Brown S.C., Phys. Rev. 74(1948) 291

[5] Honda K., Japan I.E.E.68 (1948) 92

[6] Takeda S. and Dougal A.A., J. Appl. Phys. 31(1960) 412

[7] Takeda S., J. Phys. Soc. Japan, 16(1961) 95

[8] Simonet F., Rev. Sci. Instrum. 56(1985) 664

[9] Takeda S. et al., J. Phys. Soc. Japan, 57(1988) 3036

[10] Yasuda A. et al., Rev. Sci. Instrum. 51(1980) 1652

Takeda S. and Yasuda A., Rev. Sci. Instrum. 42(1971) 394 